\title{
Differenz
}

Revista internacional de estudios heideggerianos y sus derivas contemporáneas

AÑO 7, NÚMERO 6: JULIO DE 2020. ISSN 2386-4877 - DOI: 10.12795/Differenz.2020.i06.04

[pp. 73-90]

Recibido: 20/04/2020

Aceptado: $12 / 06 / 2020$

\section{El jánico semblante del nihilismo: Heidegger y Severino ante las encarnaciones de la Nada.}

\section{The Janus-faced countenance of Nihilism: Heidegger and Severino facing the incarnations of the Nothingness.}

\author{
Jaime Llorente Cardo \\ Universidad de Valladolid-UNED-IES Campo de Calatrava (Ciudad Real)
}

Resumen:

El presente estudio se centra en la comparación crítica de la reflexión que Heidegger y Severino proponen acerca de la verdadera "esencia del nihilismo", la cual ambos localizan en el ámbito ontológico, pero mientras que para Heidegger el "nihilismo" equivale a la postura según la cual del "Ser" ya no queda nada, Severino lo identifica con la oculta convicción de que el ente es nada. En este sentido, se examinan las perspectivas que ambos filósofos asumen en referencia a cuestiones tales como la relación entre "nihilismo" y "valor" o el ambiguo papel jugado al respecto por la subjetividad.

Palabras clave: Heidegger; Severino; Ser; Nada; Subjetividad. 


\section{Abstract:}

The present study focuses on the critical comparison of the reflection proposed by Heidegger and Severino about the true "essence of nihilism", which both locate in the real of ontology, but while for Heidegger "nihilism" equals the position according to which there is nothing left of "Being", Severino identifies it with the conviction that the entity is nothing. In this sense, the perspectives that both philosophers asume in reference to issues such as the relationship between "nihilism" and "value" or the ambiguous role played by subjectivity in this regard are examinated.

Keywords: Heidegger; Severino; Being; Nothingness; Subjectivity.

\section{Introducción: la proteica faz del nihil.}

El término "nihilismo", como es bien sabido, constituye un concepto de naturaleza particularmente proteiforme y polisémica, permanentemente ligado a los avatares histórico-epocales que lo conjugan y recrean en cada momento. Desde su auroral ocurrencia en las postrimerías del siglo XVIII en el marco de la recusación formulada por Jacobi contra el idealismo fichteano, hasta sus célebres "orígenes" ligados a la vanguardia literaria rusa del XIX (Turgéniev o incluso Dostoievski), el "nihilismo" no ha hecho sino mudar de piel y mutar de semblante ${ }^{1}$. Las acepciones del término son, de hecho, tan profusas y heteróclitas que de ordinario suele evocarse, en contexto filosófico, como significación más o menos canónica y comúnmente aceptada, aquella formulada por Nietzsche y según la cual "Nihilismo: falta la meta; falta la respuesta al '¿por qué?' ¿qué significa nihilismo? -que los valores supremos se desvalorizan"2. Y, sin embargo, más allá de referencias habituales, lugares comunes y tópicos al uso, se dan fundamentalmente dos posiciones, comúnmente pertenecientes a la esfera de la ontología contemporánea, que asumen sendas posturas originales frente al desafío formulado por las encarnaciones que el nihilismo, transmutando una vez más su tornadizo cariz, ha venido a asumir en nuestra época. Nos referimos a las posiciones adoptadas al respecto por Martin Heidegger y Emanuele Severino.

1 Como indica Franco Volpi en su monografía acerca de la historia del nihilismo, éste: "como expresión de tentativas artísticas, literarias y filosóficas dirigidas a experimentar la potencia de lo negativo y a vivir sus consecuencias, ha traído a la superficie el malestar profundo que hiende como una grieta la autocomprensión de nuestro tiempo. Ya Nietzsche lo apostrofaba como 'el más inquietante' de los huéspedes. Mientras tanto, este huésped siniestro merodea ahora por todas partes de la casa" (VoLPI, F. El nihilismo. Madrid, Siruela, 2007, p. 13).

2 NieTZSCHE, F. Fragmentos póstumos (1885-1889). Vol. IV. Madrid, Tecnos, 2006, p. 241. 
Se trataría, pues, en lo que sigue, de confrontar el singular pensamiento ontológico de Emanuele Severino, grandísimo pensador italiano fallecido en enero de este mismo año 2020, tal como éste cristaliza, sobre todo, en su obra Essenza del nichilismo (1972, edición ampliada: 1982), donde sustancia con mayor grado de acuidad sus posiciones referentes a este concepto, con la postura adoptada al respecto por Heidegger. Postura asumida en diversos lugares de su vasta producción, de los cuales atenderemos aquí fundamentalmente a lo vertido al respecto en un tratado relativamente poco conocido de idéntico título al de Severino: Wesen der Nichilismus (1946-1948), así como en su célebre "monografía" sobre Nietzsche (1961). A lo largo de toda su extensa obra, Severino define en general el "nihilismo" como aquella convicción, certeza o "fe" conforme a la cual el devenir de los entes es real, esto es, tiene lugar realmente el tránsito del Ser a la Nada y de la Nada al Ser- que se halla en el basamento más profundo de la cultura occidental en su integridad: que constituye, de hecho, el "inconsciente" perpetuamente oculto propio de Occidente mismo. Pero esta desatinada "fe en el devenir" implica a su vez -y ello representaría, al decir de Severino, "el inconsciente del inconsciente de Occidente"- la asunción de la "extrema locura" según la cual "el ente es nada", dado que, en la medida en que proviene de la nada y se halla abocado a disolverse en ella (a aniquilarse), "es" en cierto modo "nada" incluso durante el lapso onto-temporal en el que aún "es". En la mirada anuente dirigida a este imposible y en extremo teratológico hermanamiento entre los abismalmente distantes extremos ontológicos encarnados por el "Ser" y la "nada", es donde radica propiamente la "esencia del nihilismo".

El nihilismo no consiste, pues, sino en la convicción de que "el Ser es nada" y que el fenómeno que así lo atestigua (el "devenir" de las cosas, su "aparecer" y "desaparecer") constituye la más incuestionable de todas las evidencias. En el seno de esa evidencia suprema crece la totalidad de fenómenos que habitualmente conocemos como "tradición occidental" y es ella la auténtica instancia común que, de modo tácito, unifica su aparente dispersión y su difícilmente reductible diversidad:

La idea de ser sobre la que se edifica piensa, sí, el ser como lo positivo que se opone a la nada, pero lo piensa, a la vez, como algo que ejerce tal oposición sólo cuando es y, por tanto, lo piensa como aquello a lo cual le está permitido (ia él, al ser!) no ser (es decir, ser la nada), según lo que le sucede a las diferencias que se manifiestan como devinientes ${ }^{3}$.

3 SeVerino, E. Essenza del nichilismo. Milán, Adelphi, 2005, p. 26 (Las traducciones son nuestras). Así, al comienzo de la sección "Risposta ai critici" del propio Essenza del nichilismo, Severino escribe explícitamente: "Nello scritto intitolato Ritornare a Parmenide (...), viene compiuto il tentativo di rintracciare e portare alla luce il pensiero fondamentale che guida e raccoglie la sterminata richezza 
Así pues, tanto Heidegger como Severino coinciden inicialmente en señalar y localizar el fenómeno del nihilismo de un modo que incardina a éste en un contexto ontológico relativo al modo de comprensión de aquello que significa esencialmente "ser", desvinculando así el adjetivo "nihilista" de su original y proverbial raigambre ético-política. Aquello que quepa entender por "nihilismo" dependerá ahora, pues, del modo en el que se determine qué se entiende propiamente por "Ser" y "ente" y cuáles son las implicaciones de toda índole que se derivan del modo de concebir los referentes efectivamente denotados por tales términos.

Sin embargo, el segundo (Severino) critica al primero (Heidegger) por el hecho de localizar la "esencia del nihilismo" en el exclusivo atenimiento al ente en detrimento del Ser o pretiriendo aquel "acontecer" no-óntico, no-entitativo, que posibilita, sin embargo, la aparición y donación de todo ente "objetivamente" dado. Con ello, Heidegger habría soslayado la que Severino considera genuina actitud nihilista: aquella para la cual tales entes y la nada se identifican ontológicamente. En efecto, en La determinación del nihilismo según la historia del Ser, Heidegger caracteriza el rasgo esencial propio de la disposición nihilista en los siguientes términos:

Admitiendo que el ente es gracias al ser y nunca el ser gracias al ente; admitiendo asimismo que el ser, respecto del ente, no puede ser nada, ¿̇no estará el nihilismo allí donde no sólo del ente sino incluso del ser no hay nada, no estará jugando su juego o, más bien, no estará sólo allí jugando el juego que le es propio? Efectivamente. Donde sólo del ente no hay nada puede que se encuentre nihilismo [tal sería la postura severiniana, al menos parcialmente], pero no se acierta aún con su esencia, que sólo aparece donde el nihil afecta al ser mismo. La esencia del nihilismo es la historia en la que del ser mismo no hay nada ${ }^{4}$.

Al comienzo del mencionado tratado Das Wesen des Nihilismus, Heidegger incide sobre la misma intuición fundamental:

El nombre "nihilismo" (...) afirma que en aquello que nombra es esencial el nihil (nichts). Nihilismo significa: la nada está en relación con el ente (mit dem Seienden ist es nichts); y por cierto en modo alguno sólo en relación

di categorie ed eventi in cui consiste la civiltà dell'Occidente: il pensiero in cui ormai tutto viene pensato e vissuto e che non si lascia pensare nel suo significato autentico, sino a che non ci si sappia portare al di fuori di esso, lungo un camino ancora intentato. II pensiero dominante dell'Occidente è il nichilismo: I'atteggiamento, in cui I' ente in quanto ente viene pensato e vissuto come un niente" (Ib, p. 287).

4 HeIDEgGeR, M. Nietzsche II. Barcelona, Destino, 2000, pp. 275-276. 
con este o aquel ente, sino que la nada está en relación con el ente en cuanto tal en su totalidad (nichts ist es mit dem Seienden als solchem im Ganzen $)^{5}$.

Así pues, la fórmula "nihilismo" mienta, antes que nada, la "cercanía" de la nada al ente e incluso su constitutivo aherrojamiento a él: al ens qua tale, a todo ente; una proximidad o pertenencia cuyo reconocimiento es postulado por el propio Heidegger como condición sine qua non fundamental para que un pretendido pensador demuestre hallarse verdaderamente "dentro de la filosofía"6. En efecto, Heidegger comienza su itinerario en pos de la "esencia del nihilismo" reconociendo que:

Nietzsche piensa precisamente el ser, es decir, el ente en cuanto tal, y de este modo comprende mediatamente al nihilismo como una historia en la que algo acontece con el ente en cuanto tal, [de donde se desprende que] el nombre "nihilismo" nombra, a su manera, el ser del ente?

Sin embargo, Heidegger adopta un enfoque hermenéutico acerca de tal "nihilismo ontológico" conforme al cual no sólo se trata de suponer "que en lo que nombra el nombre 'nihilismo' la nada ejerce su esencia, en el sentido de que del ente en cuanto tal, en el fondo, no 'hay' nada", que en la palabra "nihilismo" "pensemos en el nihil, la nada, a una con la circunstancia de que algo ocurre en el ente en cuanto tal"8, sino que la verdadera esencia del nihilismo únicamente se muestra y torna patente allí donde el nihil de la negatividad no se limita a incidir sobre el ente, sino que atañe y corresponde al propio "Ser" de tal ente. Desde luego, a ojos de Severino, la noción de "nihilismo" se halla estrechamente ligada al "Ser del ente", tanto es así que, de hecho, como hemos tenido cumplida oportunidad de señalar, mienta precisamente aquella postura (aquella "convicción") conforme a la cual acaece la imposible convergencia entre lo máximamente positivo (el ente que "es") y su némesis ontológica: lo máximamente negativo (la Nada). El antídoto teórico capaz de ejercer un efecto verdaderamente disolutivo sobre el "nihilismo" metafísicamente entendido consiste, pues, concediéndole la palabra al propio Severino, en comprender el hecho fundamental de que:

5 HeIDegger, M. Metaphysik und Nihilismus. GA 67. Frankfurt am Main, Klostermann, 1999, p. 177. 6 He aquí el pasaje alusivo a ello: "La prueba más dura, pero también la más infalible de la fuerza y autenticidad pensante de un filósofo es la de si en el ser del ente experimenta de inmediato y desde su fundamento la cercanía de la nada. Aquel a quien esto se le rehúsa está definitivamente y sin esperanzas fuera de la filosofía" (HeidegGer, M. Nietzsche I. Barcelona, Destino, 2000, p. 370). 7 HEIDEGGER, M. Nietzsche II. Op. cit. pp. 274-275.

$8 \mathrm{lb}$. 
El ser que no es cuando no es, no es otra cosa que el ser hecho idéntico a la nada, el ser que es nada, el positivo que es negativo. El ser no es significa precisamente que el ser es la nada, que lo positivo es lo negativo9.

En este aspecto al menos, la concepción del nihilismo que identifica a éste con la convicción -explícita o inconsciente- de que la totalidad de lo existente es "nada", supone un -tal vez inesperado y oculto- acercamiento inicial de posturas entre Heidegger y Severino, dado que ambos, cada uno a su modo y desde prismas ontológicos propios, reconocen en tal identificación el fondo más profundo del pensar nihilista. Basta, a la hora de verificar tal tesis, comparar las recién escuchadas palabras de Severino acerca de la espuria identidad entre Ser y nada con estas otras pronunciadas por Heidegger en 1937:

El nihilismo, podemos decir orientándonos por la palabra, es un acontecimiento o una doctrina en la que se trata del nihil, de la nada. La nada es -tomada formalmente- la negación de algo, más precisamente, de todo algo. Todo algo constituye el ente en su totalidad. La posición de la nada es la negación del ente en su totalidad. De acuerdo con ello, el nihilismo contiene, explícita o implícitamente, la siguiente doctrina fundamental: el ente en su totalidad es nada ${ }^{10}$.

A partir de este punto de tangencia crucial, las divergencias entre ambos pensadores, comienzan al prestar atención a ciertas ramificaciones y derivas que el nihilismo (ontológicamente entendido como la convicción de que "el Ser -o el ente- es nada") irradia en dirección a diversos aspectos directamente relacionados con instancias pertenecientes a la reflexión filosófica más o menos "tradicional". A este respecto, trataremos de elucidar en lo sucesivo -de forma necesariamente somera- dos rasgos esenciales estrechamente vinculados al pensamiento nihilista tanto según los postulados asentados por el pensar del Ser heideggeriano como por la ontología neoparmenídea propuesta por Severino: el "pensamiento del valor" y la "metafísica de la subjetividad".

\section{El nihilismo como reemplazo del Ser por el "valor" y de la evidencia por la "fe".}

9 SeVERINo, E. Op. cit., p. 22. Y por ello: "Pensar 'cuando el ser no es', es decir, pensar el tiempo de su no ser, significa pensar el tiempo en el que el ser es la nada, el tiempo en que se celebra el romance (tresca) nocturno del ser y la nada. Aquello que la oposición del ser y de la nada rechaza es precisamente que haya un tiempo en el cual el ser no sea, un tiempo en el cual lo positivo sea lo negativo" (Ib).

10 HeIDEGgeR, M. Nietzsche II. Op. cit. p. 351. 
Heidegger postula una estrecha vinculación -explicitada sobre todo a partir de la Kehre, pero ya tácitamente presente en los cursos anteriores a ésta- entre "nihilismo" y "pensamiento del valor". De hecho, a su juicio, es realmente la posición del "valor", el elevar la "valoración" y el "valorar" a la categoría de instancias ontológicas capitales, el acto que en mayor medida contribuye a difuminar y oscurecer definitivamente la atención al Ser más allá del atenerse habitual y cotidiano a los entes. Rasgo que justamente, como acabamos de constatar, constituye a sus ojos la genuina "esencia del nihilismo". El "valorar" sustituye y reemplaza, de hecho, al propio "Ser"; extremo al cual Heidegger apunta cuando enfatiza el hecho de que en el pensamiento nietzscheano:

El ser es determinado como valor y con ello se lo explica desde el ente como una condición puesta por la voluntad de poder, por el "ente" en cuanto tal. El ser no es reconocido como ser. Este "reconocer" quiere decir: dejar que ser impere en toda su cuestionabilidad desde la mirada dirigida a su proveniencia esencial (...). Al representar que, al pensar en términos de valores, dirige su mirada hacia la validez, el ser le queda fuera de su círculo visual respecto ya de la cuestionabilidad del "en cuanto ser". Del ser en cuanto tal no "hay" nada: el ser, un nihil${ }^{11}$.

Como al respecto señala correctamente R. Ávila:

Heidegger se pregunta: ¿por qué tiene que haber un fundamento? ¿Qué conexión interna existe entre fundamento y valor? En esto consiste el giro desde la axiología (Nietzsche) hasta la ontología (Heidegger) (...). Estas consideraciones permiten a Heidegger señalar que, aunque Nietzsche reconoce y experimenta el nihilismo como ningún otro, su concepto de nihilismo es todavía nihilista, pues lo entiende exclusivamente desde la idea del valor ${ }^{12}$.

11 HeidegGer, M. Nietzsche II, Op. cit., p. 275. Como señala al respecto certera y concisamente Juan A. Estrada: "Heidegger acusa a Nietzsche de ser el último metafísico que ha anunciado la muerte de Dios para sustituirlo por el hombre como dador de sentido. En cuanto que se hace del hombre un principio y fundamento, mediante la racionalidad o la voluntad de poder, se cae en el nihilismo que ignora la diferencia ontológica (...). El giro de Heidegger busca superar los residuos subjetivistas de los años veinte, mientras que Nietzsche permanecería preso en un humanismo sui generis. Se mantiene la comprensión del ser como valor y una subjetividad creativa que confunde lo óntico con lo ontológico, el ente con el ser (...). Dejar el ámbito del ser por el del valor, lleva a juicio de Heidegger, tanto a la metafísica como a la civilización científico-técnica y con ellas al nihilismo" (EstradA, J. A. "La crisis axiológica y el nihilismo en Heidegger", en Pensamiento. Revista de investigación e información filosófica. Vol. 74, no 281, 2018, p. 557).

12 Ávila Crespo, R. "Heidegger y el problema de la nada", en Pensamiento. Revista de investigación e información filosófica. Vol. 63, no 235, 2007, pp. 73-74. 
De esta forma, si tomamos como premisa provisoria el hecho de que el Ser no es ya "Ser", sino "valor", cabe cuestionar si en cuanto tal "es más o menos que el Ser", dado que en este caso se tornaría manifiesto o accedería a la patencia algo más elevado que el Ser: algo "superior" y excelente con respecto al mero "Ser" ontológicamente localizado y teorizado. Así, en tanto que "valoración", esto es, en cuanto condición de su propia seguridad situada en la Wille zur Macht, el valor es "la durabilidad (Beständigkeit) de aquello que es durable (Beständigem)"13 y a la vez, en tanto que perspectiva ya asumida bajo el prisma de esa misma "voluntad de poder", encarna el "devenir" ligado al flujo perpetuamente mutable de la "vida". Pero la noción de "devenir", entendida al modo nietzscheano, remite, conforme a la interpretación que Heidegger propone acerca de ella, a "aquello que deviene (das Werdende) a lo cual debe serle impreso el carácter del ser y que por eso hay que pensar como el ente en su ser"14, al modo tradicional instituido por el pensar metafísico. No obstante, con ello, precisamente gracias a este acto que signa la impronta del "Ser" en el cambiante seno de un "devenir" perenne, el Ser permanece como un elemento "puesto" por la "voluntad de poder", es decir, continúa mostrando el reconocible carácter de una "valoración". El nihilismo sobrevive paradójicamente mediante la inoculación de la "estabilidad y durabilidad" del Ser en el proteico magma de lo que deviene ${ }^{15}$. Sin embargo, el pensamiento de Nietzsche, en la medida en que concibe la totalidad de lo existente como "voluntad de poder" (en el sentido de una metaphysica generalis) y dado que esa misma "voluntad de poder" que instituye valores es simultáneamente la "realidad" de aquello que opera verdaderamente (el Ser), piensa aún, según Heidegger, "el ser en cuanto ser y no en cuanto valor"16.

Así, cuando es solamente la "voluntad de poder" la instancia última y originaria desde y merced a la cual acontece toda posible posición y todo virtual emplazamiento de valores, el pensamiento que opera exclusivamente en términos de "valoración" asume la categoría y la dignidad propias de un principio: un principio ciertamente "nihilista", pero en un

13 HeIDEgGER, M. Metaphysik und nihilismus. Op. cit. p. 195.

$14 \mathrm{lb}$.

15 De hecho, señala explícitamente Heidegger: "La certeza (Gewissheit) como seguridad (Sicherheit) solamente puede devenir principio si la seguridad es ya considerada como valor supremo, si la estimación del valor (Wertschätzung) en cuanto tal resulta cumplida, es decir, si la posición del valor, por su parte, se ha dado cuenta de su principio" (Ib, p. 182).

16 lb. p. 196. Tal vez a esta aparentemente paradójica luz cabría comprender la hermenéutica heideggeriana acerca del sentido del pensamiento de Nietzsche cuando ésta conduce a aseveraciones como la siguiente: "En la interpretación del ser como valor la nada del ser queda sellada, de lo que forma parte que este sellar mismo se comprenda como el nuevo sí al ente en cuanto tal en el sentido de la voluntad de poder, es decir, como superación del nihilismo" (HEIDEGGER, M. Nietzsche II, Op. cit., p. 293). 
eminente y singular sentido. El correlato previsible -y aun necesario- de tal "principio" no puede sino ser, en rigurosa consonancia consigo mismo, un pensar ontológico en el cual, según el dictamen de Heidegger, no sucede solamente que "del ser no hay nada", sino que además no puede, propiamente hablando, haberlo, dado que ni "es admitido por principio en cuanto ser" ni "podría darse aquí jamás con el ser algo digno de cuestión, es decir, el ser en cuanto ser"17. La consecuencia de ello la constituye con toda evidencia la imposibilidad de que en el interior de semejante horizonte el nihilismo resulte rebasado o "superado" en modo alguno, habida cuenta de que el impulso hipotéticamente tendente al logro de tal "superación" no "podría ni siquiera ponerse en movimiento"18. El disolutivo veneno de lo axiológico corrompe e intoxica, pues a radice el pensamiento ontológico -o "el pensar del Ser" tout court- y contribuye en mayor y más decisiva medida que ninguna otra instancia a oscurecer y velar las preguntas fundamentales propias de éste ${ }^{19}$. Ahora bien, en caso de aceptarse la tesis conforme a la cual el nihilismo admite ser caracterizado como aquella historia en la cual del Ser no queda ya "nada", o donde "nada" pasa ya con él, la propia esencia del nihilismo se mostrará refractaria a ser pensada y en general experimentada si en el pensar del Ser y para él no hay nada. De ello se sigue, al decir heideggeriano, que el nihilismo cumplido queda así absoluta y terminantemente relegado y expulsado del horizonte que podría conducirnos, de forma eventual, a fijar y determinar la "esencia del nihilismo" misma.

De este modo, a juicio de Heidegger, determinar correctamente esa "esencia del nihilismo" en orden a propiciar hipotéticamente su efectiva "superación", pasa acaso, constatado todo lo anterior, por redefinir el sentido nihilista de la propia noción de "nada"; por liberar al concepto de "nada" de las connotaciones (y aun denotaciones), prejuicios, prevenciones y adherencias axiológicas de carácter "negativo" ("vacío", "irrealidad",

\section{7 lb. p. 277.}

$18 \mathrm{lb}$. El dictamen de Heidegger es, pues, concluyente al respecto: "La metafísica de Nietzsche no es, por lo tanto, una superación del nihilismo. Es el último enredarse en el nihilismo. Mediante el pensar en términos de valor a partir de la voluntad de poder, si bien se atiene a reconocer al ente en cuanto tal, al mismo tiempo, con la soga de la interpretación del ser como valor se ata a la imposibilidad de siquiera recibir al ser en cuanto ser en la mirada cuestionante. Sólo mediante este enredarse consigo mismo el nihilismo llega a terminar totalmente lo que él mismo es. Este nihilismo así terminado, perfecto, es el acabamiento del nihilismo propio" (Ib).

19 Así: "Dado que, en cuanto Nietzsche experimenta el nihilismo como la historia de la desvalorización (...) de los valores supremos y piensa la superación del nihilismo como el contramovimiento en la forma de la transvaloración (...) de todos los valores válidos hasta ahora, y precisamente en base al principio expresamente reconocido de la posición de valores, él piensa precisamente 'el ser' como valor, es decir, el ente en cuanto tal, y de este modo entiende indirectamente el nihilismo como una historia en la cual sucede algo con el ente en cuanto tal" (HEIDEGGER, M. Metaphysik und nihilismus. Op. cit., p. 182). 
etc.) con las que la metafísica occidental ha venido tradicionalmente lastrándola ${ }^{20}$. A tal respecto, Heidegger señala que:

Evidentemente, la opinión corriente y la convicción que ha tenido hasta ahora la filosofía están en lo correcto: la nada no es un "ente", no es un "objeto". Pero no se sosiega la pregunta de si esto no-objetivo sin embargo no "es", en la medida en que determina lo esenciante (das Wesende) del ser. Se mantiene la pregunta de si aquello que no es un objeto y no puede nunca ser un objeto "es" ya por ello la nada y ésta, algo "nulo". Surge la pregunta de si la esencia más íntima del nihilismo y el poder de su dominio no consisten precisamente en que se considera a la nada sólo como algo nulo y al nihilismo como un endiosamiento del mero vacío, como una negación que puede compensarse inmediatamente con una vigorosa afirmación. Quizás la esencia del nihilismo esté en que no se tome en serio la pregunta por la nada (...). ¿Pero si la nada no fuese un ente pero tampoco nunca lo meramente nulo? ¿Y si entonces la pregunta por la esencia de la nada no estuviera aún planteada de modo suficiente con el recurso a aquel "o bien -o bien" ¿Y si, finalmente, la falta de esta pregunta desplegada por la esencia de la nada fuera el fundamento de que la metafísica occidental tenga que caer en el nihilismo ${ }^{21}$

Pero ¿rehabilitar en este sentido la noción de "nada" no implica tal vez una recaída en un tipo de "nihilismo" más profundo y potencialmente deletéreo que aquel que trata de suprimir y "superar"? En este punto es donde entran en escena las posiciones adoptadas por Severino en referencia a la localización de la auténtica esencia del "nihilismo" y al subsiguiente diagnóstico susceptible de conducir a la verdadera superación de éste.

En efecto, desde el punto de vista adoptado por la ontología severiniana, Heidegger, al igual que el resto de los "habitantes de Occidente", secunda inadvertidamente la fe (la valoración) conforme a la cual:

cuando el ente, al devenir algo pasado, ha devenido una nada, es una nada. Cuando es nada, es nada (Quando è niente è niente). Y no es verdad, por tanto, que al poner un tiempo en el que el ente no es, se piense que el ente es nada. Cuando el ente es nada, es nada, dicen. Pero la alienación esencial

20 En este sentido, Leyte no deja de recordar pertinentemente que: "lejos de constituir el nihilismo este vacío, es más bien contra lo que actúa. En efecto, nihilismo es también ese reconocimiento de que el vacío (la falta de un estado para la verdad, el bien y la belleza) no puede regir" (LEYTE, A. Heidegger. Madrid, Alianza, 2005, p. 216).

21 HeIDEGGER, M. Nietzsche II. Op. cit., pp. 50-51. 
consiste justamente en la convicción [que no deja de ser una peculiar

"valoración"] de que exista un "cuando eso -ies decir, el ente!- es nada"22.

Así pues, los "habitantes del tiempo", al postular la identidad entre la nada y el tiempo (sea cual fuere) en el que el ente es una "nada" (el "cuando no es": el tiempo, en suma), creyendo establecer la identidad de la nada consigo misma, lo que afirman realmente es la identidad entre el ente y la nada: entre el "ser" y el "no-ser". Identidad tan imposible como desatinada e insensata que, de modo tácito, se constituye precisamente "al aceptar el tiempo, es decir, el 'cuando el ente es nada'"23. Pero la fe en la existencia efectiva del tiempo demanda el paralelo convencimiento de que lo que "es" , lo existente, sea nada: la persuasión de que haya un momento en el que "el ente no es" (un "cuando" en el que es nada). Solamente si se identifican los extremos abismalmente distantes y opuestos representados por el Ser y la nada, puede el tiempo mismo "ser", pero esta identificación implica el absurdo del "no ser de lo que es" y, apostilla Severino, "

la nulidad del ente (nientità dell'ente) es el nihilismo y el nihilismo es la alienación esencial. La civilización occidental crece en el interior de la convicción [compartida por Heidegger] de que el ente es en el tiempo, es decir, de que el ente es nada ${ }^{24}$.

Pensar la Nada como una instancia que "incumbe" o "afecta" al ser mismo, como señala explícitamente Heidegger, supone acaso un paso decisivo en la dirección nihilista indicada por Severino, si no su no explicitado cumplimiento mismo. También para el pensador de Messkirch el "devenir", la inquietante cercanía entre Ser y nada, constituye tal vez, como para el resto de la filosofía occidental, una evidencia a preterir: un dato Selbstverständlich, "comprensible de suyo".

Tanto es así que, al decir de Severino, la aparición o mostración de tal "nulidad" de todo lo existente, lejos de constituir una experiencia que nos resulte vedada o una suerte de "revelación racional" dificultosamente accesible sólo a unos pocos, representa inversamente la más palmaria y común de las evidencias: aquella ligada a la contemplación

22 SeVerino, E. Gli abitatori del tempo. La struttura dell'Occidente e il nichilismo. Milán, Rizzoli, 2009, p. 36.

$23 \mathrm{lb}$.

24 lb. pp. 35-36. El propio Heidegger se refiere a lo que él llama "nihilismo auténtico" en los siguientes términos: "pensamos ahora este nombre en cuanto nombra el nihil. Pensamos la nada en cuanto incumbe (angeht) al ser mismo. Pensamos este 'concernir' (angehen) mismo como historia (...). La esencia del nihilismo auténtico es el ser mismo en el permanecer fuera del juego de su desvelamiento (Ausbleiben seiner Unverborgenheit), el cual, en cuanto suyo, es él mismo y determina en el permanecer fuera de juego, su 'es'" (HEIDEGGER, M. Metaphysik und nihilismus. Op. cit., p. 221). 
del "devenir" de las cosas. "Devenir" entendido aquí, como indicamos al comienzo, en su sentido más radical, a saber: como aquel periplo ontológico que los existentes recorren ante nuestros ojos y que los conduce a alzarse desde la nada hasta el ser para revertir, en un momento posterior, de nuevo en la nada ${ }^{25}$. Un proceso fácilmente observable, en principio, en el marco de una actividad tan corriente como seguir el rastro del humo de un cigarrillo desde el instante antes de ser encendido éste (cuando aún "no es") hasta el momento posterior a su total consunción (cuando "ya no es"): "acaso no es manifiesto, acaso la experiencia no atestigua que todas estas cosas, que son, al principio no eran y ahora ya no son porque han cedido su puesto a otras?"26. Y, sin embargo, tal supuesta evidencia inmediatamente incontestable, cuando es escrutada más de cerca, en realidad no se da en absoluto. En efecto, señala Severino, "si el devenir se entiende de este modo [como salida y regreso a la nada por parte de los entes], no existe, de hecho, experiencia del devenir"27. Y ello fundamentalmente porque "quien afirma la experiencia de la aniquilación, debe afirmar que todo lo que se aniquila desaparece en la medida en que se aniquila", lo cual implica, a su vez, que "si la experiencia del desaparecer no es experiencia de la aniquilación del ente que desaparece", entonces "la experiencia no experimenta de ningún modo la aniquilación: justamente porque la experiencia de la desaparición no es experiencia de la aniquilación" 28 .

Así pues, desde la perspectiva asumida por la ontología severianiana, el supuesto fenómeno del "aniquilamiento" de los entes (el desaparecer del ente que desaparece) no admite en modo alguno ser identificado legítima y justificadamente con su tránsito a la "nada", con el devenir entendido como paso al "no-ser" (al nihil absolutum)29. Precisamente por ello, la "persuasión", "creencia" o "fe en el devenir" así comprendido (como la llama expresamente Severino: fede nell'divenire) no deja de constituir una proyección de carácter axiológico sobre el estatuto ontológico de aquello que así "deviene", es decir, a su particular modo, "una valoración". Severino obvia el empleo del

25 Frente a ello, Severino enfatiza una vez más el hecho de que "el ser no sale de la nada y no vuelve a la nada, no nace y no muere, no hay un tiempo, una situación en la que el ser no sea. Si era en la nada, no era; si volviese a la nada, no sería (...): lo que para nosotros significa que toda cosa, por muy despreciable que sea, si es una cosa, es eterna" (SEVERINo, E. Essenza del nichilismo. Op. cit., p. 57). $26 \mathrm{lb}$.

27 SeVerino, E. El parricidio fallido. Barcelona, Destino, 1991, p. 204.

28 lb. pp. 208-209.

29 De hecho, conforme a la óptica severiniana: "afirmar que 'la experiencia del desaparecer no es la experiencia de la aniquilación del ente que desaparece' significa que la experiencia, y por tanto la experiencia del desaparecer, ni siquiera se pronuncia sobre la aniquilación del ente que desaparece, de manera que no se pronuncia sobre la aniquilación de aquel ente que desaparece, que es el mismo aparecer del ente que desaparece" (Ib., p. 209). 
término "valoración", pero su sentido es delatado -como implícitamente contenido- en la expresión "presupuesto injustificado", que sí utiliza de modo explícito incardinándola además en un marco relativo a la detección del "nihilismo" larvadamente presente en el modo ordinario de expresión ${ }^{30}$. He aquí, en cualquier caso, el nudo o nexo fundamental que constituye el decisivo punto de tangencia (o convergencia) entre el diagnóstico vertido por Heidegger acerca del nihilismo nietzscheano y la ontología "antinihilista" de Severino.

De esta forma, a ojos de Heidegger, el nihilismo esencial se cumple -tanto en el marco de la metafísica tradicional como en la versión invertida de ésta representada por la "metafísica" nietzscheana de la "voluntad de poder"- al ocupar el "valor" aquel lugar reservado para el "Ser", reduciéndolo así a "nada" (nihil): consumando "el nihilismo auténtico, esto es, el hecho de que del Ser mismo, que ahora ha devenido valor, no queda ya nada"31. Y, simultáneamente, de modo paralelo, bajo la mirada de Severino es el ente (todo ente) el que resulta identificado con la nada y reducido a ella merced a una suerte de "valoración" arbitraria y espuria que soslaya tanto las evidencias fenomenológicas (no se da en absoluto experiencia de la aniquilación del ente que desaparece, sino únicamente experiencia de su salida del horizonte fenomenológico o "cerco del aparecer") como las exigencias de un lógos absolutamente refractario a acoger en su seno la "extrema locura" que supone postular que el "ser" es "nada" o que lo absolutamente "positivo" resulta idéntico a lo supremamente "negativo". También la fe en que las cosas transitan del Ser a la nada y de la nada al Ser constituye una peculiar "valoración", aunque no sea más que debido al hecho de que, ateniéndonos estrictamente a las pautas marcadas por Severino, en puridad y buena lógica no puede constituir propiamente otra cosa. "El ente es nada ( $n$ ihil)": he aquí una acendrada encarnación del nihilismo que, de forma indirecta y larvada, entronca con la admonición heideggeriana conforme a la cual el injerto de la esfera axiológica en el dominio de la ontología redunda en la "aniquilación" o "nihilización" del Ser mismo. De este modo, la de Heidegger y la de Severino se muestran a esta luz -con todas sus divergencias- como sendas formas, o al menos "tentativas", de poner al descubierto el vínculo esencial dado entre "nihilismo" y pensamiento del "valor".

30 Atiéndase, a este respecto, a un pasaje tan altamente ilustrativo como el siguiente: "En la base de este razonamiento [la justificación nihilista del desaparecer-aniquilamiento] está el presupuesto injustificado de que el 'des-aparecer' sea un 'faltar', entendido como 'ir a parar a la nada'. El presupuesto de que el desaparecer sea un apagarse, derretirse, disolverse y, por lo tanto, aniquilarse del aparecer. En este presupuesto se deja sentir el peso que el nihilismo tiene sobre el lenguaje" (Ib., pp. 211-212).

31 HeIDEgGeR, M. Metaphysik und nihilismus. Op. cit., p. 208. 


\section{El carácter ambiguo de la subjetividad.}

El nexo existente entre "nihilismo" y "subjetividad" reviste un cariz muy diferente al representado por la recién elucidada ligazón entre pensar nihilista y "ontología axiológica". Contemplada desde las perspectivas asumidas por Heidegger y Severino, la mismidad del sujeto, la subjetividad, la "conciencia", cabe ser entendida desde una doble perspectiva fundamental: bien como fuente del "ocaso" del aparecer del Ser, como instancia decisivamente contribuyente a la obliteración de su "desvelamiento" (Heidegger), bien como el ámbito "topológico" en cuyo interior -y sólo en él- acontece la patencia de lo eternamente existente que, en tal espejo privilegiado, aparece eternamente ante sí mismo (Severino). Así pues, por un lado, en el caso de Heidegger, el itinerario de la crítica a la primacía de la "subjetividad" en tanto que responsable parcial del nihilismo, se halla jalonado por tres hitos fundamentales. El primero de ellos vendría representado por la célebre crítica formulada en Sein und Zeit en referencia a la ausencia de tematización y al soslayo del modo del ser del sum del cogito llevados a cabo por la filosofía cartesiana, así como por la práctica totalidad del subsiguiente pensamiento moderno ${ }^{32}$. El segundo, por la denuncia de la sustitución del antiguo hypokeímēnon "substancial" de cuño aristotélico (y "objetivista") por la "subjetividad" del subiectum. Finalmente, el tercer hito lo constituiría la descripción heideggeriana del modo en el que acaece históricamente la transmutación del "sujeto" (en los albores de la modernidad filosófica) en eje autoafirmado y dominador absoluto de todo lo objetivamente dado, convertido ahora en mero obiectum en el marco de la Zeit des Weltbildes, es decir, de tal modernidad interpretada como "época de la imagen del mundo". De ahí la posibilidad de la noción misma de Weltanschauung, dado que solamente para un "sujeto" observador puede haber algo semejante a una imago mundi o el mundo puede devenir en general "imagen".

Estos tres "hitos" coadyuvan a la hora de propiciar el oscurecimiento y el olvido de la "cuestión del Ser" y, por tanto, también a la de preparar un expedito camino al advenimiento del "nihilismo" tal como lo hemos definido con anterioridad. Así, por

32 En su carta-ensayo de "respuesta" a Ernst Jünger Zur Seinsfrage, Heidegger consigna al respecto la siguiente reflexión: "Para que la idea de la esencia humana pueda alcanzar el rango de lo que fundamenta ya a todo presente como la presencia que permite primero una 'representación' en el ente y así legitima a éste como el ente, tiene el hombre ante todo que ser representado en el sentido de un fundamento normativo. Pero, ¿normativo para qué? Para el asegurarse del ente en su ser. ¿En qué sentido aparece 'Ser' cuando se trata del asegurarse del ente? En el sentido de lo en todas partes y en todo tiempo constatable, es decir, representable. Descartes, entendiendo así el Ser, encontró la subjetividad del subiectum en el ego cogito del hombre finito. El aparecer de la forma metafísica del hombre como fuente de donación de sentido es la consecuencia última de la posición de la esencia humana como subiectum normativo" (HEIDEGGER, M.; JüNGER, E. Acerca del nihilismo. Barcelona, Paidós, 2010, p. 89). 
continuar rastreando la esencia de éste a través del ya mencionado escrito Metaphysik und Nihilismus, Heidegger reconoce en él que la subjetividad, en cuanto constituye ella misma una particular forma de "desvelamiento" (Unverborgenheit), porta aún por ello tenues vestigios del modo helénico de concebir la esencia de la verdad como a-lètheia. En esta medida, el rasgo esencial de la "verdad del ente" ha de ser captado desde el fundamento representado por tal "esencia de la verdad", es decir, teniendo en cuenta que "la subjetividad es la verdad de la objetividad en la cual se manifiesta el Ser del ente en la edad moderna"33. No obstante, "subjetividad" y "verdad del ente" se identifican sólo en la medida en la cual el sujeto se halla "puesto" en la certeza del saberse a sí mismo, lo cual implica que la "certeza" deviene aquí rasgo esencial de la propia "verdad del ente". Así, el acto "representativo", la Vortellung del sujeto, se muestra como una instancia idéntica al propio saber entendido como "conciencia". Es de esta forma, según Heidegger, como, a través del modo como el sujeto se asegura de sí mismo y de sus representaciones "propias", la verdad del ente -comprendido como Gewissheit- incorpora asimismo el carácter de la "certeza". Con ello, "ser representado" no significa ya, en este contexto, "la adecuación a un ser-presente (Anwesenheit) no pensado en su ser-presente (Anwesendes)", sino que la corrección comparece aquí en términos de determinación de todo lo susceptible de ser representado en general conforme a un criterio fundado en la "exigencia de saber propia de la res cogitans, sive mens, que representa" 34.

Frente a ello, Heidegger postula que el evento de "mutua pertenencia" (Zusammengehörigkeit) merced al cual hombre y Ser se apropian de manera recíproca (el Ereignis), en cuanto acaece (ereignet) más allá del horizonte "sujeto-objeto" tradicionalmente instituido por la metafísica, acontece al margen de esa subjetividad cierta de sí que desempeñaba espuriamente el papel de "verdad del ente" en el marco de la metafísica moderna. La iniciativa corresponde, pues, en el seno del "evento apropiador" heideggeriano, siempre al Ser ${ }^{35}$. La inversa afirmación de la subjetividad auto-fundada como certitudo suprema y originaria no redunda sino en "velamiento" (justo el término inverso a Verborgenheit) y preterición del Ser mismo en cuanto tal, y con ello en incursión

33 HeIDEGGER, M. Metaphysik und nihilismus. Op. cit., p. 187.

34 lb. p. 188.

35 François Fédier ha captado y explicitado con agudeza este rasgo fundamental: "le substantif choisi pour traduire Ereignis n'a pas été 'appropiation'. Car, bien que Littré donne comme première acception de ce terme: I'action d'appropier, nous avons tous presque automatiquement tendance 'a entendre 'appropiation' comme le fait, pour un sujet, de s'appropier quelque chose, de s'en rendre posseseur. 'Appropriement' (...) me paraissait aller heureusement en sens inverse de ce contresens, dans la mesure où, son suffixe pointant plus intensément sur l'oeuvre en cours, le mot lui-même dit non pas que quelqu' un s'appropie quelque chose, mais bien que: appropiement il y a" (FÉDIER, F. Entendre Heidegger. Et autres exercises d'ecoute. París, Le Grand Souffle, 2008, p. 145). 
en el "nihilismo" definido ahora como perspectiva según la cual, frente a la subjetividad del sujeto, "el Ser es nada". El "desvelamiento del Ser" no es, por tanto, propiamente hablando, cosa del "hombre" o del "sujeto" en primer término, sino acontecimiento que tiene lugar originalmente a instancias del Ser mismo. Así, haciendo gala de su característico sesgo antisubjetivista, Heidegger señala que:

La esencia del nihilismo no contiene nada negativo, en el modo de algo destructivo que tuviera su sede en las convicciones humanas y se ejerciera a través de las acciones humanas. La esencia del nihilismo no es en absoluto cosa del hombre, sino del ser mismo, y por ello, entonces sí, es también cosa de la esencia del hombre y, sólo en esa secuencia, al mismo tiempo cosa del hombre; y presumiblemente no sólo una más entre otras ${ }^{36}$.

Y, sin embargo, contemplada desde el punto de vista asumido por Severino, la ambigua duplicidad que virtualmente muestra "lo subjetivo" en el marco ontológico de reflexión acerca del nihilismo, se muestra en toda su ordinariamente inadvertida patencia. En efecto, Severino, al contrario que Heidegger, no abandona y rechaza el lenguaje propio de la "metafísica subjetivista", pero sólo para concebir la subjetividad, bajo sus múltiples denominaciones, en términos de sede "topológica" privilegiada en cuyo interior acontece la manifestación de un "Ser" tan sempiterno como su aparición y como la pantalla subjetiva en el cual ésta refulge ${ }^{37}$. En este sentido, Severino escribe reveladoramente:

El Ser está destinado a aparecer. En este destino reside la esencia del hombre. El significado originario del "alma", la "mente", el "pensamiento", la "conciencia", etc. es su ponerse como aparecer del Ser. Y "yo" significa el aparecer en cuanto tiene como contenido a sí mismo, es decir, expresa de forma concisa la identidad de la forma y del contenido. El hombre no sólo es eterno, como todo ente, sino que es también el lugar (luogo) en el que lo eterno se manifiesta eternamente ${ }^{38}$.

36 HeIdegGer, M. Nietzsche II. Op. cit., p. 295.

37 Aunque Paolo Poma, crítico de Severino, no deja de indicar pertinentemente que: "È curioso constatare come il nichilismo abbia inicio col pensiero dell'eternità dell'essere (Parmenide) e come pervenga alla propria conclusione (...) con quello dell' eternità di tutto l'essere (neo-parmenidismo di Severino). Infatti, è 'nichilismo' ritenere, assieme a Parmenide e (...) con Platone e gli abitanti della Reppublica da lui fondata (I'Occid-ente), che l'ente sia ni-ente; ma è parimenti 'nichilismo' il pensiero del destino, perché la terra mostra la Necessità del divenire" (POMA, P. Neccesità del devenire. Una critica a Emanuele Severino. Pisa, ETS, 2011, p. 26).

38 SeVerino, E. Essenza del nichilismo. Op. cit., p. 198. 
Así pues, el ego cartesiano-moderno se muestra ahora como necesario espejo ontológico que permite la eterna revelación de la totalidad de lo eternamente existente. La "subjetividad", el "yo", la "conciencia" son considerados, de este modo, en términos de "este lugar eterno en el cual nacen los mundos (questo luogo eterno in cui nascono i mondi)"39. El carácter esencialmente ambiguo de la subjetividad reside, pues, en que, mientras que para Heidegger se trata de la instancia en buena medida responsable del fatídicamente nihilista "olvido del Ser", a ojos de Severino aparece como aquel emplazamiento ontológico que desmiente perpetuamente todo posible atisbo de nihilismo metafísico.

\section{Conclusión.}

Como acabamos de ver, tanto Heidegger como Severino piensan comúnmente el fenómeno del nihilismo a la luz de la comprensión del Ser, aunque desde puntos de vista divergentes. La comparación entre ambos resulta filosóficamente sugestiva en la medida en que coinciden en un aspecto fundamental que constituye su aportación propiamente original, a saber: concebir el "nihilismo" como una suerte de carencia de visión, de penuria en la apreciación de lo percibido, de "defecto" de observación. Como una singular variante de ceguera o ablepsia ontológica que conduce, bien a soslayar el Ser de los existentes dejando subsistir solamente la manifestación de éstos, bien a interpretar la "evidencia" del devenir como prueba palmaria de que los entes salen de la nada y van a parar a ella, con lo que son "nada" incluso "cuando" y "mientras" son ${ }^{40}$. La superación efectiva del "nihilismo" pasaría, por tanto, según esto, por un acto de reeducación o redefinición de la mirada "fenomenológica" en virtud del cual ésta lograse sacudirse su secular aletargamiento para encarar finalmente aquello que ya desde siempre se despliega y muestra ante ella ${ }^{41}$. Contemplado desde este prisma de observación, el hipotético acto de rebasamiento del nihilismo constituiría una particular variante de "anámnēsis visual": de rememoración perceptiva de aquello que jamás se ha apartado de la vista de los "habitantes de Occidente", pero que éstos han desdeñado encarar, que temen acaso

\section{9 lb., pp. 164-165.}

40 Así: "La experiencia fundamental de Nietzsche dice: el ente es y en cuanto tal, el ente no es nada. Por consiguiente, el nihilismo según el cual del ente en cuanto tal no hay nada permanece excluido de los fundamentos de esta metafísica. Ésta, por tanto, ha superado (überwunden) el nihilismo" (HeIDEgGer, M. Metaphysik und nihilismus. Op. cit., p. 206.).

41 De ahí que a su pregunta "¿adónde lleva esta Auseinandersetzung con Nietzsche (...) por el ser que es al mismo tiempo Nichts, nada?", Vincenzo Vitiello responda: "Ileva a ninguna parte; o, mejor, lleva allí donde estamos desde siempre" (VITIELlo, V. "Heidegger y el nihilismo" en Er, Revista de Filosofía. № 29, 2000, p. 17. 
encarar. Tanto el pensamiento de Heidegger como el de Severino representan enérgicos revulsivos contra tal renuencia.

\section{Referencias bibliográficas.}

Ávila CReSPo, R. "Heidegger y el problema de la nada", en Pensamiento. Revista de investigación e información filosófica. Vol. 63, no 235, 2007, pp. 59-79.

EstradA, J. A. "La crisis axiológica y el nihilismo en Heidegger", en Pensamiento. Revista de investigación e información filosófica. Vol. 74, no 281, 2018, pp. 549-565.

FÉDIER, F. Entendre Heidegger. Et autres exercises d'ecoute. París, Le Grand Souffle, 2008. HeIDEgGER, M. Metaphysik und Nihilismus. GA 67. Frankfurt am Main, Klostermann, 1999. HeIDEgGer, M. Nietzsche I-II. Barcelona, Destino, 2000.

HeIDEgGer, M.; Jünger, E. Acerca del nihilismo. Barcelona, Paidós, 2010.

LEYTE, A. Heidegger. Madrid, Alianza, 2005.

NietZSCHE, F. Fragmentos póstumos (1885-1889). Vol. IV. Madrid, Tecnos, 2006.

PomA, P. Neccesità del devenire. Una critica a Emanuele Severino. Pisa, ETS, 2011.

SeVerino, E. Essenza del nichilismo. Milán, Adelphi, 2005.

SeVerino, E. Gli abitatori del tempo. La struttura dell'Occidente e il nichilismo. Milán, Rizzoli, 2009.

SEVERINO, E. El parricidio fallido. Barcelona, Destino, 1991.

Vitiello, V. "Heidegger y el nihilismo", en Er. Revista de Filosofía. № 29, 2000, pp. 9-27.

VoLPI, F. El nihilismo. Madrid, Siruela, 2007. 